\title{
Metastatic Nasopharyngeal Carcinoma
}

National Cancer Institute

\section{Source}

National Cancer Institute. Metastatic Nasopharyngeal Carcinoma. NCI Thesaurus. Code C156079.

A carcinoma that arises from the nasopharynx and has metastasized to another anatomic site. 